Homepage: http://epubs.icar.org.in/ejournal/index.php/JWR

\title{
Effect of abiotic stresses and mitigation strategy associated with their tolerance in wheat
}

\author{
Sudhir Kumar ${ }^{1}$, Sunita Mahapatra ${ }^{2 *}$, Sunanda Chakraborty ${ }^{2}$ and Subhra Mukharjee ${ }^{3}$ \\ ${ }^{1}$ Department of Plant Breeding and Genetics, Bihar Agricultural University, Sabour, Bhagalpur, Bihar, India \\ ${ }^{2}$ Department of Plant Pathology, Bidhan Chandra Krishi Vishwavidyalaya, Mohanpur, West Bengal, India \\ ${ }^{3}$ Department of Genetics and Plant Breeding, Bidhan Chandra Krishi Vishwavidyalaya, Mohanpur, West Bengal, India
}

\section{Article history:}

Received: 11 Nov., 2020

Revised: 13 March, 2021

Accepted: 4 May, 2021

\section{Citation:}

Kumar S, S Mahapatra, S Chakraborty and S Mukharjee. 2021. Effect of abiotic stresses and mitigation strategy associated with their tolerance in wheat. Journal of Cereal Research 13(1): 16-37. http://doi.org/10.25174/2582$\underline{2675 / 2021 / 111211}$

"Corresponding author:

E-mail: sunitamahapatra@yahoo.co.in

(C) Society for Advancement of Wheat and Barley Research

\begin{abstract}
Global warming influences environmental factors which directly and indirectly affects agricultural crop production by exposing to several new biotic and abiotic stresses. The abiotic stresses like heat, drought, moisture, salinity and pre harvest sprouting stresses are most common whose effect became more severe due to climate change. Globally wheat is the most widely cultivated and used crops due to its economic and social values. Its production and productivity are highly vulnerable to these abiotic stresses. The development of wheat varieties tolerant to these abiotic stresses is a very challenging assignment for wheat researchers. The conventional breeding program is being practiced for such objectives but it will not be sufficient to achieve the target production and more advanced research is needed for better understanding the mechanism of these stresses and how plants became more tolerant. The progress made in the understanding of these abiotic stress tolerances is due to advances in three main research areas: physiology, genetic, and breeding research. Identifying morphological traits, physiological and biochemical traits for précised phenotyping and associated genes contributing to particular stress tolerance is very important under mitigation strategy. Previous studies showed that some abiotic stress tolerance is controlled by a polygene and its genetic constitution will help to analyze the gene network(s) controlling stress tolerance. Furthermore, stress mitigation options particularly through the application of plant hormones, several agronomic interventions, genetic and biotechnological management strategy are convenient for improving plant performances under various abiotic stresses are also essential to stabilize the wheat productivity.
\end{abstract}

Key words: Climate Change, Abiotic stress, Wheat, Morphological, Physiological, Biochemical, Genetic, Mitigation strategy.

\section{Introduction}

Wheat is the second most important cereal crop of the world providing $21 \%$ of total food calories after rice and largest source of protein $(21 \%)$ to feed the 4.5 billion population of developing countries (Braun et al., 2015). It covers about 220 million hectares area (mha) with a production of 716 million tons of food grain with a productivity of 3.2 tons per hectare (Oshino et al., 2011).
However, Asian countries occupies 45\% of total wheat area with productivity 2.33 ton per hectare as much below the global average and contributed only 33 per cent in global wheat production (FAO, 2010-11) Its demand will increase in developing countries up to $60 \%$ more in 2050 over current production (Annonymous, 2011). In India wheat production and productivity was enhanced after 
Effect of abiotic stresses and mitigation strategy associated with their tolerance in wheat

the green revolution of late 1960s followed by another green revolution during 1980s (Yadav et al., 2019). These two green revolutions, contributed significantly for enhancement of wheat production and productivity which results in annual growth rate in wheat production globally was $\sim 3 \%$, but simultaneously, in recent years it has declined to $<0.9 \%$ due to appearance of new biotic and abiotic stresses due to climate changes. Although currently, the global wheat production has been sufficient enough to meet the current demand and consumption, but we will have to enhance production for future need and achieve the targets of $\sim 858 \mathrm{Mt}$ up to 2050, as aligned with current global production of $763 \mathrm{Mt}$ (Gupta et al., 2020). It includes at least a $15 \%$ increase in global wheat production (1.5\% annual increase) over the next three decades to feed the world's growing population, which is expected to feed 9.7 billion people in 2050 (https:// population.un.org/wpp/). It's a difficult task to achieve this target production because of continuously shrinkage in cultivated land due to urbanization and the probable negative impact of global warming. Climate change leads to appearance of several biotic and abiotic stresses for wheat which results in lower down its quality and yield. In this connection there is need to improve its quality and productivity in order to feed a rising population on limited cultivated land. So, in the current scenario this topic is an emerging issue as in presence of all kind of stresses how could we stay with our stable production. Mitigation of abiotic stresses is the need for the hour as here we are making a war against the nature. In this review article we discussed in details about all kind of abiotic stresses we are facing day by day which effect on wheat production and at the same time describe its way out to sustain its production.

\section{Abiotic stresses and its significance}

Global temperature may play significant role on agricultural productivity in according to the severity of the several exposed abiotic stresses like high temperature, drought, salinity, water logging, and mineral toxicity. Among these abiotic stresses the wheat crop is mainly affected by water stress during critical growth stages in vegetative periods and terminal heat stress in reproductive phase. These abiotic stresses disturb the biochemical and physiological activities of crop plants which results in to more than 50\% yield reduction in various ways (Acquaah, 2007).
Drought stress can be simply defined as a scarcity of water which leads to dramatic changes in morphological, biochemical, physiological, and molecular features of the plants (Sallam et al., 2019; Kumar et al., 2020). All of these changes significantly hamper plant growth and crop production. Drought is most common abiotic stress that affects growth and development of crop plants. The yield losses in the present varieties of wheat due to moisture stress in central India can range from 11.6 to $43.6 \%$ if irrigation is provided throughout the crop season (Tiwari et al., 2014). The impact of drought stress may appear at any growth stage but the level of its adverse effects depends on stage specific stresses and the local environment. Therefore, genotypes may be tested for their drought tolerance at different growth stages. Some genotypes may show tolerance to drought at the germination or seedling stage, but these may be very sensitive to drought at the flowering stage or vice versa. Therefore, genotypes may be tested for their drought tolerance at each critical growth stages. Furthermore, a decrease in precipitation and increased evaporation as a consequence of global warming may increase the frequency of drought and its severity will increase in the future. Therefore, understanding the drought induced damages in wheat plants and approaches how to improve drought tolerance is crucial to increase wheat productivity. Recently few microbiomes have been identified that can be useful against drought tolerance on wheat (Mahapatra et al., 2020).

Heat stress induced by high temperature is expressed as increase in air temperature due to beyond a particular threshold level and period which results in irreversible damages of plant (Farooq et al., 2011). The heat stress situation becomes more intense when soil temperature increases due to the increase in air temperature associated with the decline in soil moisture. During the period from 1880 to 2012, the Earth's system warmed by $0.85^{\circ} \mathrm{C}$ (IPCC, 2014). This warming period will be continuing and is predicted to rise between the range of $1.5-4.0^{\circ} \mathrm{C}$ in the future (Wheeler et al., 2013). Likewise, CIMMYT-ICARDA predicted that global temperature will increase up to $2-3^{\circ} \mathrm{C}$ by 2050 which may results in 20-30\% of wheat yield losses in developing countries (Annoymous, 2011). Similarly, Kavita et al. (2016) mentioned that that for every $1^{\circ} \mathrm{C}$ rise in temperature above the optimal growing temperature of $15-20^{\circ} \mathrm{C}$, the duration of grain-filling is reduced by 2.8 days. 
Further, Singh et al. (2019) highlighted that continual heat stress is a problem in about $7 \mathrm{~m}$ ha area, while terminal heat stress is a problem in about $40 \%$ of the irrigated wheat growing areas of the world. High temperature affects crops yield by affecting in different ways including poor germination, plant establishment, reduced photosynthesis, leaf senescence, decreased pollen viability which leads to production of reduced number of effective tillers, number of seed per panicle with smaller grain size and consequently reduction in wheat productivity. Wheat is very sensitive to heat stress particularly in some physiological growth stages. It has been estimated that reduction in global wheat yield falls by $6 \%$ for each $1^{\circ} \mathrm{C}$ of further temperature rise while it has been estimated that the mean ambient temperature is predicted to increase by $1-6^{\circ} \mathrm{C}$ by the end of the twenty-first century (IPCC, 2014). The optimum temperature for proper growth and development of wheat crop is around $21^{\circ}$ to $24^{\circ} \mathrm{C}$. However the range of optimum temperature is specific to agro climatic zones in which it is grown. Moreover, in most of the cultivated area where rice -wheat cropping system is followed, the cultivation of long duration rice varieties leads to late sowing of wheat crop. In such conditions, it experiences heat stress particularly in post flowering stages. In the central and peninsular parts wheat crop faces heat stress throughout the crop season while significant parts of north-western and north-eastern plains experience terminal heat. So the farmers in north-western, central India and north-eastern plains zone prefer early sowing of wheat to escape terminal stress (Misra and Varghese 2012). Wheat crop when exposed to high temperature i.e. above the optimum range in any critical growth stages results in yield reduction.

Globally, salinity affects over $20 \%$ of the world's cultivable land, and its region is growing by the day due to environmental change and anthropogenic activities. (Munns et al., 2008). It has been assessed that overall 20\% of all out developed and 33\% of irrigated agricultural lands are influenced by high salinity. In India, it is predicted that $\sim 4.5$ mha area under wheat is salt affected (Jasrotia et al., 2018). A saline soil is described as one in which the electrical conductivity (EC) of the saturation extract in the root zone exceeds $4 \mathrm{dS} \mathrm{m} 1$ (roughly $40 \mathrm{mM} \mathrm{NaCl}$ ) at $25^{\circ} \mathrm{C}$ and has a 15 percent exchangeable sodium. (Smruti Shree et al., 2018). The yield of wheat begins to decay at 6-8 dS m-1 (Royo et al., 2003). It has been estimated that total salt affected area in India is probably going to increment to 16.2 million ha by 2050 .

Germination of wheat seed inside the grain ear head before harvest is called pre-harvest sprouting (PHS). It also known as premature germination occurs when grain is exposed to excessive precipitation and high humidity after it has matured but before it can be harvested. Kernel swelling, germ discoloration, seed-coat parting, and root and shoot emergence are all signs of PHS (Thomason et al., 2019). Pre-Harvest Sprouting (PHS) in bread wheat is a setback that occurs to varying degrees all over the world. As the outcome of PHS, wheat qualities as well as yield are affected. It induces changes in sugar content; total protein and amino acid composition, along with enzymatic activities, are the reasons for the consistency and yield degradation. Pre-harvest sprouting is negatively associated with test weights, yield, seed viability, seedling vigour, flour yield, and baking consistency. Germinated seed products may be spongy, soggy, off-color, and of poor quality (Groos et al., 2002). Farmers and food processors can suffer significant financial losses as a result of reduced grain quality and yields caused by PHS.

Water logging is characterized as a state of the soil in which water remains on the surface for an extended period of time or where the available water fraction in the soil surface layer is at least $20 \%$ higher than the field water potential. It adversely affects crop production in about 4.5 million hectares in irrigated soils of the Indo-Gangetic plains of northern India (CSSRI 1997). Estimated 20-25\% yield loss can happen depending upon plant damage; it may exceed $50 \%$ due to severe water logging condition. Singh et al. (2020) have reported 50 per cent reduction in grain yield of bread wheat under waterlogging conditions. Water logging tolerance is defined as survival or the maintenance of high growth rates, biomass accumulation or grain yield under water logging relative to non water logged (usually drained soil) conditions (Setter and Waters, 2003). Water logging is one of the most dangerous natural phenomena, and it may also be referred to as flood, submergence, soil saturation, anoxia, and hypoxia, depending on the moisture or water level on the ground. Generally, two types of flooding are present in the field: (1) water logging, in which root and some portion of the shoot goes under water (Anoxia), and (2) complete submergence, where 
Effect of abiotic stresses and mitigation strategy associated with their tolerance in wheat

the whole plant goes under water (Hypoxia). Almost a total of over 22 million hectares of lowland cultivable area worldwide are vulnerable to flash flooding, which damages almost 18\% of the global wheat supply (Mohanty et al, 1985). Out of that 10 million hectares of land in India and Bangladesh are regularly affected by flood in monsoon season regularly (Huke and Huke, 1997). In case of wheat, water logging causes degradation of chlorophyll, protein, RNA, and also reduces the concentration of nutrients like nitrogen, phosphorus, metal ions, and minerals in shoot. After the onset of flood leaf chlorosis starts (Wang et al., 1996), root and shoot growth was also affected which results in reduction of accumulation of dry matter and also finally in yield (Malik et al., 2002) Researchers suggested that it is a combined effect of reduced kernel and tiller numbers which is responsible for reducing yield of wheat in water logging. It has been estimated that 20-40 \% yield loss can happen depending upon plant damage (Collaku et al., 2002) and it may be reach up to $50 \%$ due to severe water logging (Setter et al., 2003).

\section{Effect of different abiotic stresses on wheat production}

\subsection{Drought Stress}

Drought stress is very much sensitive to plant growth and development; it leads to leaf wilting, stunted plant growth. Under deficient soil moisture, seed unable to germinate or show impaired germination and on progress it shows poor crop stand establishment. Water stress in vegetative phase reduces the numbers of effective tillers, number of seed per panicle, number of days to heading, peduncle length, and shortens the anthesis period, while at post-anthesis stage; Post-anthesis period when exposed to drought stress causes detrimental effect on pollination, fertilization and seed development and shortens the duration of grain filling, seeds per panicle, fresh and dry biomass production, maturity period etc. which cumulatively results in reduced grain yield. Drought has a negative impact on many other abiotic stress related plant parameters, including relative water content, leaf area index, dry matter accumulation, and net assimilation rates. Drought stress has a negative impact on plant physiological processes at various stages of development, including germination, vegetative growth, reproductive, and maturity. Under such stress conditions plant limits the stomatal opening which restricts the photosynthesis, respiration, transpiration, uptake and transportation of water and nutrient and translocation of assimilates.

Drought stress damages the cell membrane structure, disorganization of ultra-structural cellular components and disruption of its properties, enzyme activities and anion and cationic imbalance are some of the major reasons for disturbing plant physiological processes. Drought stress causes the formation of reactive oxygen species (ROS). Hydrogen peroxide $\left(\mathrm{H}_{2} \mathrm{O}_{2}\right)$, superoxide $\left(\mathrm{O}_{2}\right)$, singlet oxygen $\left({ }^{1} \mathrm{O}_{2}\right)$ and hydroxyl radicals $\left(\mathrm{OH}^{-}\right)$ are the most common species which are generated due to iron-catalyzed Fenton reaction due to the activities of lipoxygenases, peroxidases (POX), NADPH oxidase, and xanthine oxidase. The ROS in any form causes substantial damage to cell components and can cause cell death (Hasanuzzaman et al., 2013).

\subsection{Heat Stress}

The effects of heat stress on plants are very complex; it affects crops in different ways including germination, plant growth and development, physiological, biochemical and cumulatively its effect in yield reduction (Fig. 1). It affects as poor germination, degree of such effect varies depending on the crops, cultivars, phenological stages, sowing dates and management practices. Heat stress is a serious threat, particularly during reproductive and grain-filling phases, that results into yield loss (Pandey et al., 2019). It has been observed that the grain yield of wheat per spike was reduced by $3-4 \%$ per $1^{\circ} \mathrm{C}$ increase in temperature above $15^{\circ} \mathrm{C}$. (Wardlaw et al., 1989). The effect of high temperatures $\left(>30^{\circ} \mathrm{C}\right)$ for short periods is thought to be equivalent to $2-3{ }^{\circ} \mathrm{C}$ warming in the seasonal mean temperature (Wheeler et al., 1996). Global warming due to Climate change continuously increases the environmental mean temperature.

Heat stress hampers the wheat seed germination arise due to surrounding high soil temperatures and seeds experience delay in germination due to altered metabolic activity. On further growth progression it has the potential to disrupt plant establishment, reduced photosynthesis, leaf senescence, decreased pollen viability, pollen development when exposed prior to anthesis and negatively impact grain number and grain filling duration, reduced seed size on exposure during reproductive phase which results in reduced grain yield. 


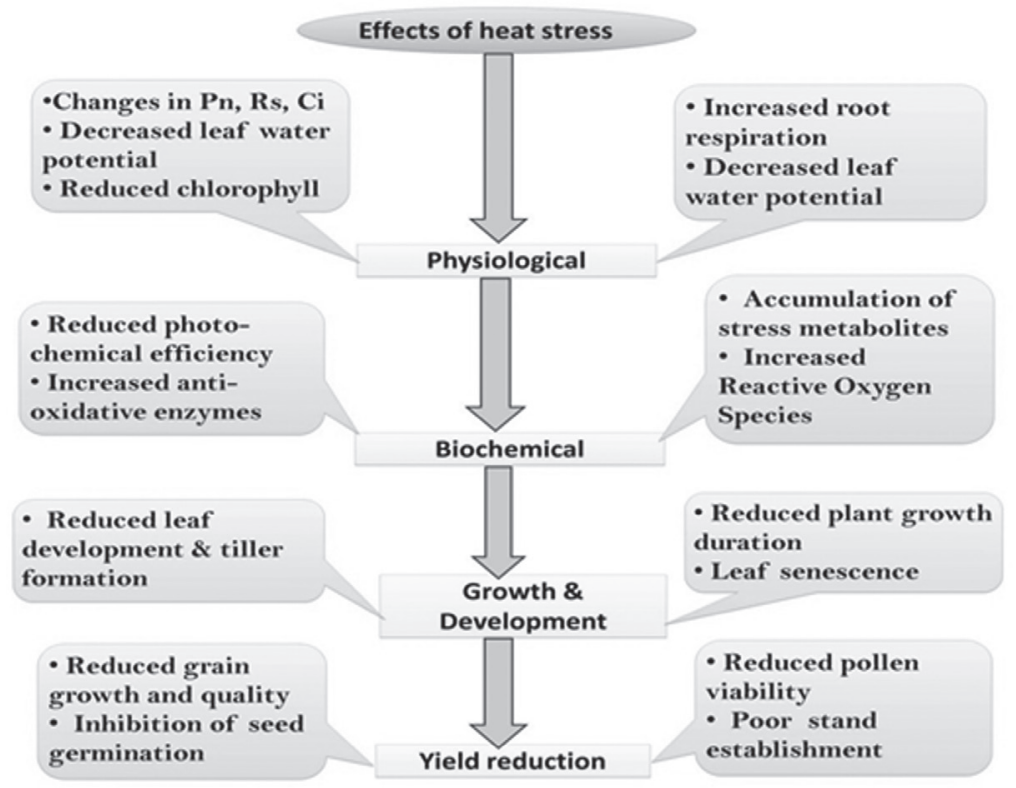

Fig. 1 Major effects of heat stress on plants growth and development. Pn, Rs, and Ci indicate photosynthesis, stomatal conductance, and intercellular $\mathrm{CO}_{2}$ concentration respectively (Akhter et al., 2017)

\subsection{Salinity}

High salts concentration in the soil affects plant growth from germination to harvesting. Salinity is one of the most damaging abiotic stresses, affecting plant morphological, physiological, and biochemical characteristics such as germination, growth, water uptake, photosynthesis, nutrient uptake, enzymatic activities, and yield. Higher salinity causes lower germination rate, photosynthesis, transpiration, and higher accumulation of $\mathrm{Na}^{+}$and $\mathrm{Cl}^{-}$ions which disturb the normal metabolic processes of wheat plants (Fig 2). It may affect the plants in two ways, either by decreasing the rate of water entry into plants results in osmotic stress immediately, reduces cell expansion in root tips, young leaves, and causes stomatal closure (Munns and Tester, 2008) or by promoting the entry of toxic ions. The osmotic ability of the root-zone soil solution is usually related to crop growth reduction due to salinity.

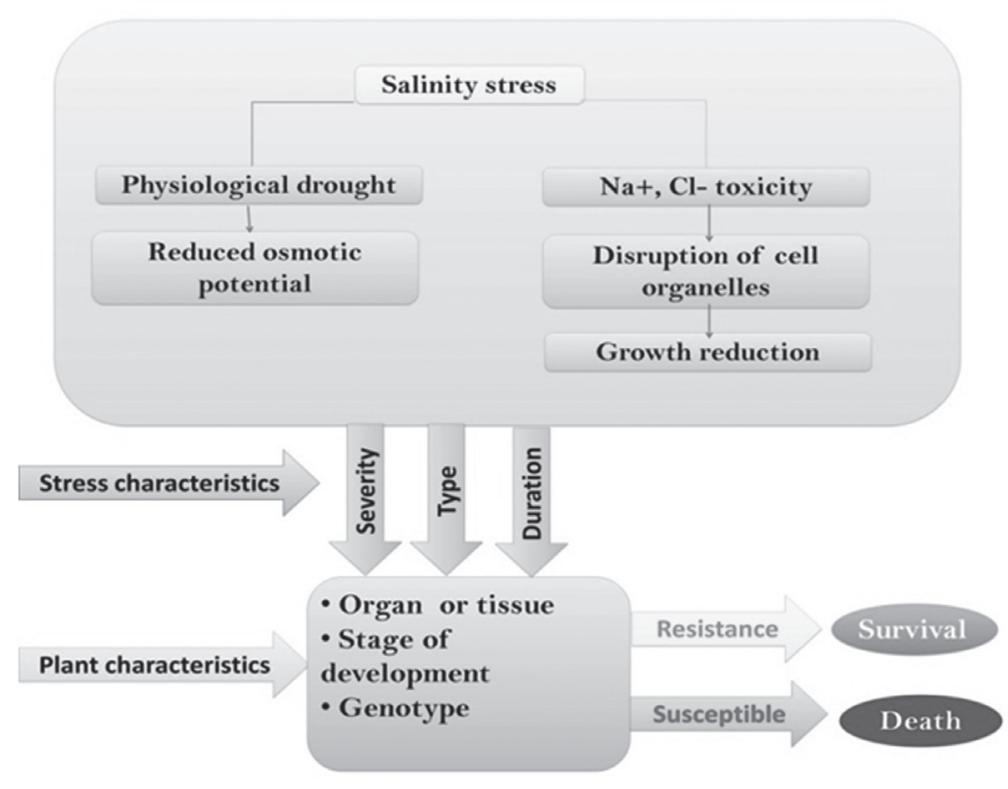

Fig. 2: Effect of salt stress responses on plants adaptation (Hasanuzzaman et al., 2017) 
Effect of abiotic stresses and mitigation strategy associated with their tolerance in wheat

A failure in $\mathrm{Na}+$ exclusion manifests its toxic effect after days or weeks, depending on the species, and causes premature death of older leaves (James et al., 2011).

\subsection{Water logging}

Water logging is a serious problem in low-laying rainfed areas. Water logging condition cause lack of oxygen supply for the plant which hampers nutrient and water uptake, as a result the plant shows wilting. In oxygen-deprived condition plants shift its metabolism to anaerobic from aerobic mode. To cope with the oxidative stress, plants that can withstand it have mechanisms such as increased availability of soluble sugar, aerenchyma formation, increased activity of glycolytic pathway and fermentation enzymes, and involvement of antioxidant defence mechanisms (Ahmad et al., 2013). When water recedes and $\mathrm{O} 2$ re-enters the soil and root tissues, the formation of reactive oxygen species (ROS, e.g., superoxide, hydroxyl radicals, singlet oxygen and hydrogen peroxide) might especially damage cell membranes. ROS production is a consequence of a low energy charge, high level of reducing equivalents and saturation of the mitochondrial electron transport chain, favoring electron leakage to $\mathrm{O}_{2}$ upon reaeration (Blokhina et al., 2003). ROS can be detoxified by defense mechanisms including enzymes (e.g., superoxide dismutase) and antioxidants (e.g., ascorbate, glutathione). Water logging causes degradation of chlorophyll, protein, and RNA and also reduces the concentration of nutrients like nitrogen, phosphorus, metal ions, and minerals in shoot. After the onset of flood leaf chlorosis starts further root and shoot growth were also affected by, resulting in a decrease in dry matter accumulation and eventually in yield (Malik et al., 2002).

Wheat crop when grown in salt affected with waterlogged soil, the yield reduces significantly by reduction in grain weight, length of spike and spikelet number. The traits mostly to be affected on exposed to water logging stress is mainly determined by the stressed crop growth stages. Water logging at early vegetative stages reduces tillering and hence spikes per plant, water logging at anthesis stage can reduce numbers of florets and hence grains per spike, and water logging during grain filling can reduce weight of individual grains (de San Celedonio et al., 2014; Marti et al., 2015).

\subsection{Pre-Harvest Sprouting (PHS)}

Pre-harvest sprouting in bread wheat is a setback that occurs to varying degrees all over the world. The problem arises when standing full-grown wheat crops are subjected to excessive precipitation and high humidity prior to harvest, and seeds in the spike sprout. Sprouted seeds have a higher -amylase activity, which causes starch degradation, sugar content changes, total protein by modifying amino acids, enzymatic activities, and lower bread consistency.

\section{Physiological, biochemical and developmental responses of abiotic stresses in wheat plants}

\subsection{Early Vigour}

A more prominent biomass/early ground cover by plant canopy during early development stages gives more productive water usage by soil mulching and subsequently diminishing in evapo transpiration from the soil. In this way, remaining soil moisture will be used by the plants for a longer period under extreme stress condition to survive. By implication, early vigour also leads to a deeper root system. This trait might be utilized as an appropriate selection criterion under a range of moisture stress conditions. It very well may be measure rapidly and effectively through a visual score or utilizing NDVI and can likewise be utilized for quick assessment of large populations (Tiwari et al., 2017).

\subsection{Osmotic Adjustment (OA):}

Osmotic adjustment (OA) maintains cell water content by increasing the osmotic power that cells can exert on their surroundings, resulting in increased water uptake. It involves the net accumulation of organic or inorganic solutes/osmolytes, total soluble sugars, total free amino acids, proline, glycine betaine, sodium chloride, and potassium in cells because of a decrease in the water potencial, As an outcome of this net accumulation, the cell osmotic potential is brought down, and turgor pressure tends to be maintained along with more water in leaf cells with more OA bringing about higher turgor as compared with leaves having less OA. Osmoregulation and turgor support permit continuous development of roots and takeup of moisture from the soil (Sharp and Davies, 1979). Free amino acids and proline accumulation contributed essentially for osmotic change in wheat flag leaves under 
salinity stress adding to higher grain yield (Bandeh-hagh et al., 2008).

\subsection{Canopy Temperature}

The high surface area of leaves makes plants most vulnerable to heat stress. A significant amount of energy is spent by all plant to maintain the cellular temperature. The leaf and its canopy temperature in plant system depend on transpiration, respiration and carbon dioxide level in leaf tissues. Direct relations with several physiological processes of plants make canopy temperature one of the best parameters for heat tolerance screening.

\subsection{Stomatal conductance}

Under field condition, when the plants are gradually exposed to heat or drought stress, the early response is the closure of stomata. Stomatal closure is likely to be mediated by chemical signals traveling from dehydrating root to shoots. One of the chemical signals involved in stomatal functioning has been identified as abscisic acid (ABA) (Daveis and Zang, 1991). Stomatal activity directly regulates the water supply through xylem (Nardini et al., 2001). Under field conditions, stomatal regulation of water loss has been established as an early event in plant response to water deficit, limiting carbon absorption by the leaves. (Chavas, 1991; Cornic and Massacci, 1996). This stomatal response has been linked more closely to the soil moisture content (Tardieu et al., 1991; Stoll et al., 2000). The first response of virtually all the plants to acute water deficit under heat and drought stress is the closure of their stomata to prevent the transpiration water loss (Mansfield et al., 1990).

\subsection{Relative Water Content (RWC)}

Assessment of water loss from excised leaves has been indicated as a good criterion for characterizing drought resistance. Leaf water status is intimately related to several leaf physiological variables, such as leaf turgor, growth, stomatal conductance, transpiration, photosynthesis and respiration. Water content and water potential have been widely used to quantify the heat stress in leaf tissues. Leaf water content expresses the relative amount of water in plant tissues. However water potential measures the energetic status of water inside the leaf cells (Slatyer and Taylor, 1960). When water uptake by roots is equal to transpiration, then RWC is about 85\% - 95\%. Critical RWC (below which tissue death occurs) varies amongst species and tissue types, it may be $50 \%$ or less. Reducing level of RWC represents the severity level of dehydration of plant tissues when it expose to water losses due to heat or other abiotic stresses (Morgan et al., 1997). Various studies revealed that increasing duration and severity of stress decreased the RWC of plants. RWC is related with grain yield under irrigation and dry land conditions. Drought-tolerant genotypes have higher RWC, and this trait can be used for screening and identification of genotypes.

\subsection{Photosynthesis}

Photosynthetic $\mathrm{CO}_{2}$ assimilation is known to be sensitive to environmental stresses (Dubey, 1997). Under high heat stress conditions, drought and salinity often are occurring simultaneously particularly in arid and semiarid areas leading to significant yield losses. Dehydration under drought stress affects the leaf $\mathrm{CO}_{2}$ assimilation and declines net photosynthesis due to stomata closure (Cornic et al., 1992) and RUBISCO activity (Bota et al., 2004).

\subsection{Transpiration}

Under heat stress or drought, a reduction in dry matter output is normally linearly related to a decrease in cumulative transpiration (Jones, 1992). Leaf expression and transpiration for various crop show sensitivity to declining plant available soil water. However, in general these processes decrease when about a third of the transpirable soil water remains in the soil (Turner, 2001)

\subsection{Membrane Leakage}

Cell membrane alteration, which results in irregular function or complete dysfunction, is a significant effect of plant environmental stress. The basic structural and functional changes caused by pressure are yet to be fully resolved. However, the cellular membrane dysfunction due to stress is well expressed through increased permeability and leakage of ions, which can be readily measured by the efflux of electrolytes. Thus, the assessment of membrane dysfunction under stress by estimating cell electrolyte spillage from influenced leaf tissue into a fluid medium is discovering developing use as a proportion of cell film security (CMS) and as a screen for stress tolerance. The CMS is positively related and explains above $70 \%$ of drought tolerance when contrasted with other physiological characteristics. 


\subsection{Chlorophyll Content Index}

Under any environmental stress, plant shows loss of chlorophyll content and the variation in total chlorophyll/ carotenoids ratio may be a good indicator of level of stress in plants. High chlorophyll content under stress is a desirable trait as it indicates a low degree of photo inhibition of the photosynthetic apparatus. Water stress condition drastically reduces the chlorophyll content. Hence, the estimation of flag leaf chlorophyll content and its stability over time can indicate resilience of the plant's photosynthetic activity and canopy temperature. The cooling efficiency of the plants through transpiration is measured by its canopy temperature. The relationship between canopy temperature, air temperature and transpiration is complex, and it involves atmospheric conditions (vapour pressure deficit, air temperature and wind velocity), soil moisture and plants canopy size, canopy architecture and leaf adjustments to water deficit.

\subsection{Chlorophyll Fluorescence}

Estimations of the moderate and the quick chlorophyll fluorescence energy have been seen to be sensitive to drought stress. The chlorophyll fluorescence has likewise displayed positive relationship with grain yield under terminal heat stress condition (Pandey et al., 2015).

\subsection{Stem Reserve Mobilization}

Stem reserves are sugars, for example, fructans, sucrose, glucose and fructose which get gathered in the stem as stores. Water soluble carbohydrates (WSC) collect up to anthesis time and partitioned to the stem from where they are later accessible as a supply for remobilization to the creating grains. These reserves are a significant source of carbon for grain filling as request regularly surpasses current assimilation, possibly contributing 20 to $40 \%$ weight of the grain in non-stressed condition (Vignjevic et al., 2015) and this can be up to $70 \%$ under stressed conditions during grain filling (Rebetzke et al., 2008). Genetic variability for stem reserve mobilization exists in wheat, and it tends to be investigated for the development of efficiency under high temperature and water stress situations Nagarajan and Rane, 2002.

\section{Selection of stress-tolerant genotypes}

Presently stress tolerant good genotypes are chosen based on high yield performance under concerned stress condition regardless of thinking about other related attributes. Be that as it may, yield assessment under stress conditions isn't generally the most appropriate selection quality. There is a methodology dependent on an assessment of some physiological attributes and natural qualities associated with stress tolerant would be a superior alternative. Normally, when plants are exposed to abiotic stress, plants attempt to limit their adverse impact by a few methods viz. stress avoidance, stress escape and stress tolerance. These mechanisms are constrained by many related segment attributes in the avoidance mechanism, the plant evades the stress through such qualities like decrease in leaf region, expanded pubescence, leaf rolling and leaf reflectance with epicuticular wax collection. In the escape mechanism, plants sense the future event of stress and accordingly alter the phenology to complete their life cycle early with the goal that the impact of stress is not appear in the genotypes. While, in the tolerance mechanism, the plant experiences stress but it can withstand the stress condition through various adaptive features. Deep root system, coleoptile length, leaf (phyllotaxy, direction and edge), pubescence, wax, stem length, peduncle length gathering osmolytes, maintaining film trustworthiness, overhang temperature and relative water content, stomatal thickness on leaf surface, stomatal conductance and other morphological, anatomical, physiological, and biochemical attributes in stress tolerance. It is realized that each genotype has different adaptive mechanisms with various related characteristics. Despite new improvements in phenotyping procedures, the identification of a single trait will represent all the variations present in the population for tolerance to abiotic stress has not been possible yet. Subsequently, there is a need to build up a protocol that can identify various traits related to abiotic stresses. Mudi et al. (2016) reported disease stress tolerance index on barley for suitable selection criteria of disease tolerance among different genotypes. Among these, few significant traits have been recognized indicating high and positive correlation with stress resilience e.g. root engineering, happening proficiency/ carbon isotope segregation, stomatal conductance, canopy temperature, osmotic alteration, stay green etc. Phenotyping for assessing the effect of specific stress conditions in wheat is normally done by correlating them with the controlled condition. 


\subsection{Characterization and selection for Drought Tolerance}

To screen drought stress genotypes of wheat, morphological, physiological, and biochemical boundaries such as root system, early vigourness, leaf pubescence, plant waxiness, stomatal density, osmotic adjustment, relative water content, membrane leakage, canopy temperature, chlorophyll content index, chlorophyll fluorescence, stomatal conductance, photosynthetic rate, and transpiration rate have been identified. None of these boundaries could turn out practically feasible for selecting individual plants from the breeding materials. Henceforth, determination of individual segregants depends on survival under natural dry conditions in which impact might bring about progress in grain yield. The segregating material can be exposed to artificial moisture stress under controlled conditions to choose drought stress tolerant and susceptible plants depending on seedling survival. The carbon isotope discrimination (CID) technique has recently been used to successfully identify drought-tolerant genotypes. (Rebetzke et al., 2002).

Deep root system, early vigour, rapid ground covering plant and waxiness etc. have been proposed as important morphological traits for screening for early drought tolerance. slower rate of leaf senescence, high osmotic adjustment, high chlorophyll content, photosynthetic rate, transpiration efficiency/carbon isotope discrimination, stomatal conductance, low canopy temperature, prolonged stay green habit etc. have an advantage in overcoming water stress. The deep root system enables plants to explore higher soil volumes and thus remain hydrated under heat and drought and permit cooling of the canopy under such stress. So that it can be a good selection index in identifying genotypes for drought and heat tolerance.

\subsection{Characterisation and selection for Heat Tolerance}

For selection of heat tolerant genotype, we have to identify the traits associated with heat tolerance in wheat through experiments conducted both in the field and under controlled environmental facilities. Selection and screening of heat tolerant genotypes is based on component traits associated with better yields under heat stress. The traits used as selection criteria for heat tolerance should be: (1) strongly correlated with grain yield under heat stress condition (2) rapid, stable, and easy to measure; and (3) highly heritable
(Edmeades et al., 2001). Potential traits for screening heat tolerance in wheat are photosynthesis rate, Leaf chlorophyll content, flag-leaf stomatal conductance, membrane stability (Reynolds et al. 1994), Canopy temperature depression etc. Genotype screening based on electrolyte leakage, an index of membrane stability, from leaves subjected to extreme temperatures, is one of the rapid screening methods (Shanahan et al., 1990). Electrolytes are collected from stressed tissue soaked in deionized water and quantified by measuring electrical conductivity. Good correlation between membrane stability and grain yield under heat stress has been found (Blum et al., 2001). Reduction of tetrazolium triphenyl chloride in mitochondria may also be used as an indicator of heat tolerance. The relative degree of tetrazolium triphenyl chloride reduction to formazan, which is detected by a spectrophotometer, is used to quantify cell viability (Towill and Mazur, 1974). A visual rating of stay-green is quick and easy way for the plant breeders to screen on mass scale ( $\mathrm{Xu}$ et al., 2000). Nonetheless, this trait may be a disadvantage as it is associated with the tendency to retain the stem reserves (Blum, 1998). ). It is established that many physiological traits/parameters, such as grain-filling time (GFD) and canopy temperature (CT), have been shown to have a close relationship with terminal heat tolerance (THT). Reduced GFD is thought to protect the plant from damage caused by terminal heat stress, while a low CT helps the plant to withstand terminal heat stress Sharma et al., 2015.

\subsection{Characterization and selection for Salt stress}

Salt stress influence the wheat crop at all phases of plant development. Hence it is basic to comprehend wheat's reaction to salt stress at each period of development which can be useful in identifying salt tolerant genotypes. The morphological characters of different plant parts such as leaf (shape, size, zone, senescence, cuticle tolerance and waxiness), root (length, root hairs, root region, new and dry weight, thickness) and others vegetative plant parts (plant height, diameter and fresh and dry biomass) are influenced. Under salinity stress conditions, the creation of ramified root framework has a significant contribution to above ground biomass. A developed root system can contribute to keep up plant development during early development 
stages and extract water and micro-nutrients from the soil. As observed in previous investigations salt stress reduces the plant leaf area which diminishes the rate of photosynthesis resulting in low biomass production (Kingsbury et al., 1984). The physiological activity of wheat is additionally hindered by saltiness at both cell and entire plant levels through ionic and osmotic pressure. These physiological processes include modification for plant development, mineral dissemination and membrane variability coming about because of calcium separation by sodium and membrane permeability (Mehta et al., 2010). High salt concentration in soil diminishes leaf water potential, loss of turgor pressure due to osmotic imbalance, results in stomatal closure, decrease in $\mathrm{CO}_{2}$ conductivity through stomata, photosynthetic rate, chlorophyll content, carotenoides, membrane variability alteration in cell wall integrity, increase in oxidative stress due to more reactive oxygen species (ROS) production and increased development of toxic metabolites. This may lead to damaging effects on the macromolecules such as DNA, RNA, proteins and lipid; it may also lead to the impairment of plant function and ultimately lead to death of the plant.

Generally reactive oxygen species (ROS) are produced in thalakoid, mitochondria and peroxisome during photosynthetic process, Electron transport chain and glyoxylate cycle respectively. Salinity tolerant genotypes have many enzymatic mechanisms under anti-oxidant defense system for scavenging of salinity induced ROS. The enzymes which are overproduced comprises of glutathione reductase (GR), glutathione synthetase, superoxide dismutase (SOD) and ascorbate peroxidase (APX). Many solutes are needed in the plant cell, including proline, glycine betaine, abscisic acid, and polyol, to maintain the osmotic potential in the vacuoles against ion toxicity accumulated in the cell compartments.

Many solutes including proline, glycine betaine, abscisic acid and polyol in the plant cell are required to retain the osmotic potential in the vacuoles against the ion toxicity accumulated in the cell compartments. These are also known as compatible solutes or metabolites as they help in protection of plant against salt stress (Sharma and Garg (1983). Identification of genotypes which overproduced these enzymes and solutes are helpful in selection of salt stress tolerant genotypes. Devi et al. (2018) demonstrated that low $\mathrm{Na}+$ concentration and high proline and chlorophyll content at seedling stage are vital physiological traits contributing towards yield under salt stress and thus can be employed as selection criteria in breeding programmes. Recently, Manohara et al. (2020) performed genetic analysis of grain yield and its associated traits in diverse salttolerant rice genotypes under coastal salinity condition and emphasis on the need of selecting salt related traits under saline environment to bring sufficient genetic improvement in plants.

\subsection{Selection and characterization for Waterlogging Tolerance}

Water logging tolerance is characterised as the ability to maintain relatively high grain yields under waterlogged conditions as compared to no or minimal waterlogging. (Setter and Waters, 2003). Tolerance to waterlogging allows plant species to develop unique morphological traits and biochemical modifications that allow crops to change their metabolism in response to oxygen scarcity in order to survive or maintain their development (Fig. 3). The mechanisms of water logging or hypoxia tolerance include: (i) the maintenance of high internal aeration through constitutive aerenchyma and the formation of an oxidised zone around root tips through radial $\mathrm{O}_{2}$ loss (Armstrong et al., 1994), (ii) metabolic adaptation that maintains energy output under hypoxia (Brandle and Crawford, 1987) with significant carbohydrate storage for fermentation under hypoxia (Brandle 1991). The developments of morphological adaptive traits to make plant water logging tolerant are growth of seminal roots and production of numerous adventitious roots with aerenchyma which increases root porosity and helps the plant to respire aerobically and to maintain growth under hypoxic conditions (Huang et al., 1994). The metabolic adaptive traits are anaerobic respiration, maintenance of carbohydrate supply for anaerobic respiration, avoidance of cytoplasmic acidification and development of antioxidative defense system (Drew, 1997; Setter et al., 1997). This system includes ascorbate (AsA), glutathione (GSH), phenolic compounds, superoxide dismutase, catalase, peroxidases, gluthatione reductase and ascorbate peroxidase (Garnczarska, 2005) etc. These morphological and biochemical adaptive traits have been identified as selection indices for selection of water logging tolerant genotypes. 


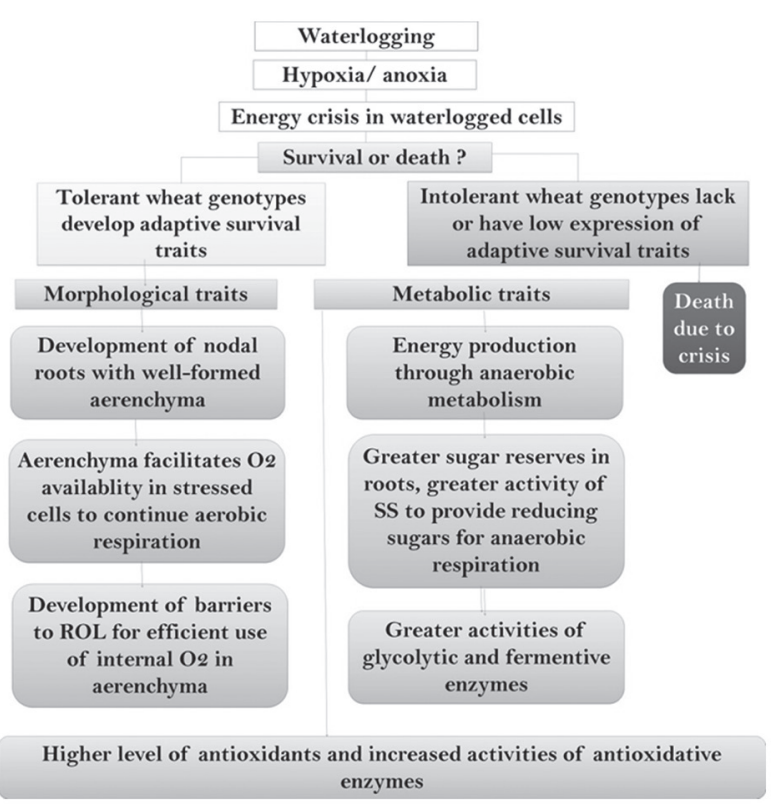

Fig. 3: Schematic diagram showing morphological and metabolic adaptive traits for waterlogging tolerance in wheat (Hossain et al., 2011)

\subsection{Traits for Characterization of Pre harvest Sprouting (PHS) Tolerance}

There are a number of methods to measure the PHS. The falling number $(\mathrm{FN})$ is the most commonly used approach to quantify PHS. It indirectly measures the activity of the enzyme $\alpha$-amylase that breaks down starch in germinating grains. Falling-number tests are conducted by creating slurry of flour and water in a test tube. The time required for a plunger to fall through the slurry is measured. Sound, starchy grain produces thick slurry (and a bigger falling number). Sprout-damaged grains will result in a flour and water mixture that is thinner or less viscous, because alpha-amylase has begun to break down the starch. The faster the plunger falls to the bottom of the test tube, the lower the viscosity of the mixture and the smaller the falling number. Lower falling numbers indicate there have been higher levels of alpha-amylase activity. Falling numbers, thus, are an indirect but quite accurate measure of PHS. In general, falling-number values less than 250 seconds to 300 seconds indicate flours that are of poor quality for milling and baking. Similar methods are amilography which determines the effect of viscosity of the alpha amylase enzyme and the rapid visco analyzer (RVA), which is also based on the ability of alpha amylase to liquefy a starch gel. Germination index estimates the rate of seed germination under controlled conditions with higher values associated with more seeds germinating earlier in the evaluation.

\section{Strategies to mitigate abiotic Stresses}

\subsection{Plant hormones}

Hormones play a significant role in acclimatizing the plant during stress conditions. There are six primary group of hormones, specifically auxin, cytokinin (CK), gibberellic acid (GA), abscisic acid (ABA), ethylene, strigolactones, brassinosteroids and jasmonic acid (Fig 4). Among all plant hormones, ABA assumes particularly significant function to maintain physiological processes under stress and hence subsequently named as 'stress hormone'. Stressinduced senescence and abscission are the key processes interceded by ABA.

Under drought stress conditions, ABA-altered root architecture is an approach to take-up more water from soil. It promotes the advancement of more profound root system alongside upgrading hydraulic conductivity in plants, maintenance of cell turgor which finally contributes to desiccation tolerance. The ABA acts as the primary signaling molecules under salinity stress and its concentration increases in plant parts exposed to salt stress. Over synthesis of ABA under stress induces stomata closure which brings about diminished stomatal conductance, photosynthetic rate and transpirational water loss Wei et al. 2017. It has also been suggested that male fertility is impacted by accumulation of endogenous $\mathrm{ABA}$ levels within the anther tissue (Ji et al., 2010). Other hormones, such as auxin, ethylene and cytokinins (CKs), may change the effect and biosynthesis of ABA. The higher ABA concentration in grains might result from auto synthesis within the grain and partly by the translocation from leaves and roots during drying. $\mathrm{ABA}$ increases the endogenous content of proline under drought conditions. Auxin is positively and ABA is negatively correlated with the activity of expansin protein under oxidative stress condition. Under stress condition, it shows down regulation of cell division and elongation (Kosova et al., 2012, Tromas et al., 2013), led to pollen sterility (Sakata et al., 2010). Pre-sowing treatment of wheat seeds with growth regulators (IAA and GA) inhibits the effect of salinity. Plant growth-stimulating compounds such as gibberellic acid, zeatin, and ethephon have been found to help mitigate the effects of salinity. (Afzal et al., 2005). On the other hand, it down regulates the seed germination and stem elongation (Fleet and Sun, 2005). Recently, Khobra et al. (2010) reported 
Effect of abiotic stresses and mitigation strategy associated with their tolerance in wheat

that exogenous application of Melatonin (N-acetyI-5methoxytryptamine) as a promising molecule to improve seedling vigour and drought tolerance in wheat.

Cytokinins (CKs) play a supportive role during water deficit conditions by stimulating osmotic adjustment while down regulating the cell division and proliferation, endosperm development, photosynthetic reserve and apical shoot meristem development. It was hypothesized that CKs could increase salt tolerance in wheat plants by interacting with other plant hormones, especially auxins and ABA. Exogenous application of kinetin overcomes the effects of salinity stress on the growth of wheat seedlings.

Ethylene is a gaseous hormone generated from S-adenosyl methionine (SAM, the same precursor for polyamines) and largely acts as a negative growth regulator (Kosová et al., 2012; Yang et al., 2017). Ethylene is primarily involved in the late stages of plant growth and development, particularly senescence, associated leaf abscission, fruit ripening, seed maturation, drying, and dispersal (Wilkinson and Davies, 2010). Ethylene release has been associated with the inhibition of root growth and leaf expansion and, if induced by severe or extended stresses, can promote extensive plant senescence, embryo abortion, and reduce grain filling (Wilkinson et al., 2012).
Brassinosteroids impart resistance to plants against variety of abiotic stresses, and are thought to have pleiotropic effects because they affect a variety of developmental processes such as seed germination, seed growth, rhizogenesis, flowering, and senescence.

Salicylic acid (SA) is an endogenous plant hormone that regulates various processes including: growth and development, germination, photosynthesis, and antioxidant regulation (Fardus et al., 2018). Exogenous application of SA in wheat led to an increased production of antioxidants, leading to reduced instances of oxidative damage under heat, drought, and saline conditions (Noreen et al., 2017). Exogenous applications of SA were used to mitigate damage caused by abiotic stresses by increasing the production of $\mathrm{H}_{2} \mathrm{O}_{2}$ in an NADPH-oxidase-dependent manner (Agarwal et al., 2005a; b).

Jasmonic acid (JA) signaling may play an important role in bridging abiotic and biotic stress tolerance. Exogenous application of $2 \mathrm{mM} \mathrm{JA}$ in wheat seedlings led to an increase in salt tolerance. It leads to increased expression and enzymatic activity of superoxide dismutase, peroxidase, catalase, and ascorbate peroxidase (Qiu et al., 2014). This resulted in the reduction of $\mathrm{H}_{2} \mathrm{O}_{2}$ and other ROS, which would otherwise be harmful to cellular survival.

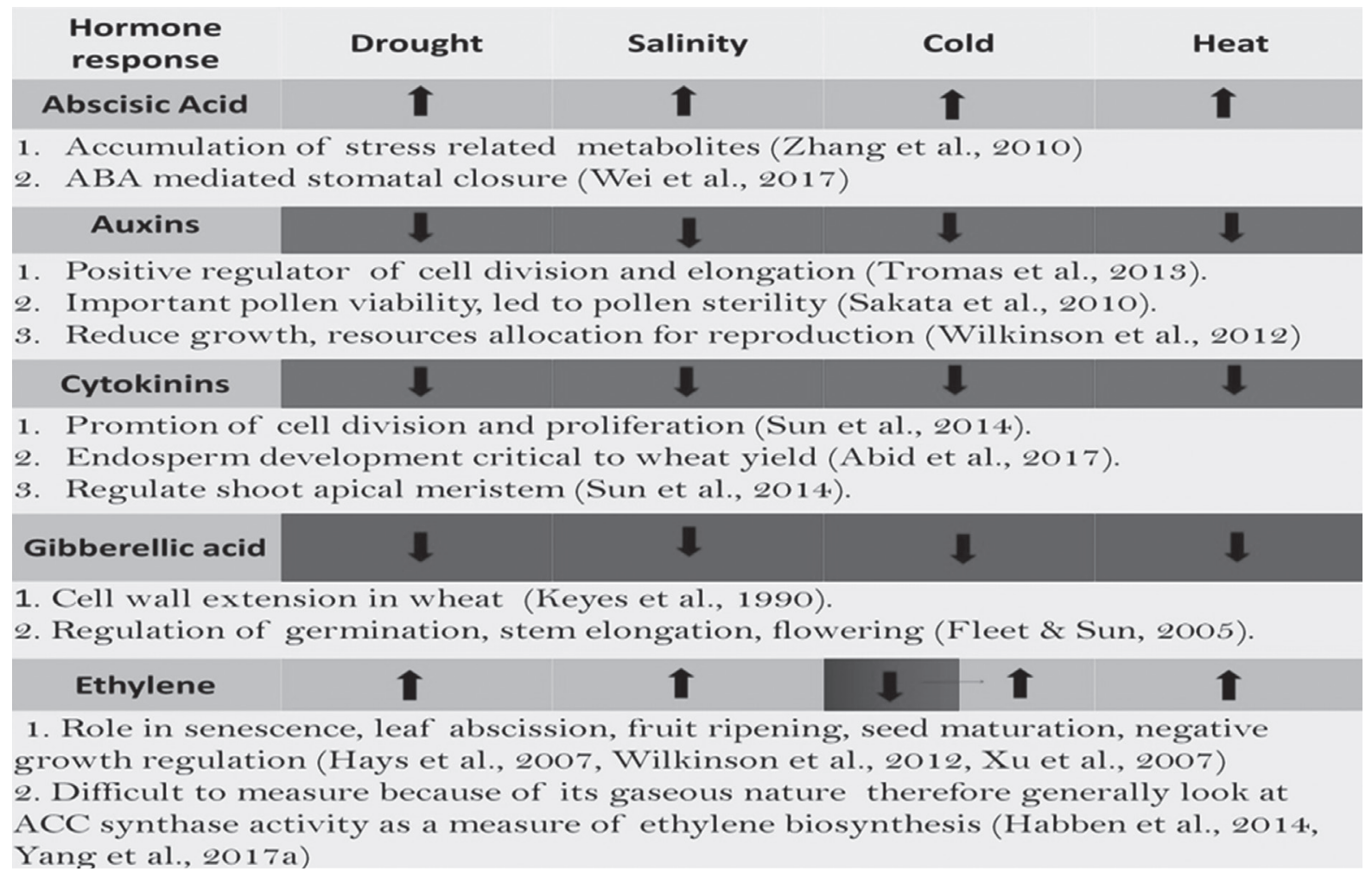




\section{Salicylic acid \\ 1

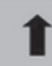

1. Activate antioxidant enzymes reducing stress related ROS (Chen et al., 2016)

2. Protection of photosynthetic thylakoid membranes (Khan et al., 2013)

3. Accumulation osmoprotectant molecules e.g., proline (Khan et al., 2013).

4. Modulate ice nucleation to reduce freezing stress (Tasgin et al., 2006).

\section{Strigolactones}

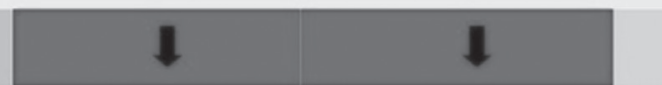

NA

NA

1. Establishment of biotic interactions in rhizosphere (Cheng et al., 2013).

2. Modulation of shoot and root architecture (Jansen et al., 2O14).

3. Response to abiotic stress (Visentin et al., 2016, Gou et al, 2017).

\section{Brassinosteroids}

1. Exogenous application increased photosynthate accumulation and $\mathrm{CO}_{2}$ fixation (Braun and Wild, 1984).

2. Exogenous application reduced level of ABA and IAA (Avalbaev et al., 2010).

3. Exogenous application enhanced resistance to heavy metal (Kroutil et al., 2010).

4. Over-expression of wheat BRII receptor leads to thermotolerance (Singh et al., 2016).

\section{Jasmonic acid}

1. Activate antioxidant enzymes to reduce stress related ROS (Qui et al., 2014).

2. JA may play important role mediating stomatal closure along with ABA (Zhao et al., 2014).

3. Modulate cross-talk between hormones under abiotic stress (Zhao et al., 2014).

Fig 4: Summary of hormonal responses [upregulated (green), down regulated (red)] following exposure to various abiotic stresses (Abhinandan et al., 2018)

\subsection{Agronomic Interventions}

Some agronomical practices are also helpful in the crop management under abiotic stresses condition.

\subsubsection{Heat Stress}

Under heat stress condition conservation agriculture has shown promising results. It involves significant reductions in tillage particularly zero tillage, mulching and adopting diversified and economically viable crop in rotations. Resource-conserving practices like zero tillage (ZT) allow early sowing of wheat after rice harvest so that the crop is able to fill the grains before the onset of heat stress (Mehla et al., 2000). Sprinkler irrigation helps in cooling of plant canopy on exposure to high temperature beyond $30{ }^{\circ} \mathrm{C}$ and reduces the adverse impact of heat stress (Shankar $e t$ al., 2015). Effect of heat stress in early growth stages like tillering or booting stage can be minimized by providing a need-based light irrigation. By moderating temperature fluctuations, conserving soil moisture, and improving soil organic matter status, conservation agriculture practises helps in the mitigation of temperature stress. Wheat sowing by zero tillage method just after harvesting of previous crop helps in early sowing and utilization of residual moisture available in soil which helps in escaping terminal heat stress and saving water required for presowing irrigation in wheat crop (Rane et al., 2007).

\subsubsection{Drought Stress}

Different methods of irrigation like furrow irrigation in furrow-irrigated raised bed (FIRB) planting system, sprinkler and drip irrigation help in efficient management of scarce water resources. Combined application of plant growth-promoting rhizobacteria (PGPR) formulated bio-fertilizer (BF) and salicylic acid (SA) enhances plant biomass, photosynthetic pigments, relative water content, osmolytes, and activities of the defense-related system under drought stress condition. It have been observed that plant treated with SA and BF together under drought stress had significantly increased leaf water status, Chl a, Chl b, and carotenoids synthesis. Moreover, the co- 
Effect of abiotic stresses and mitigation strategy associated with their tolerance in wheat

application of SA and BF showed maximum SOD, POD, APX, and CAT activities in the leaves and roots under drought stress which makes plant more tolerant to stress (Azmat et al., 2020).

\subsubsection{Salt stress}

Saline soils are reclaimed by scraping of salts by using mechanical ways; flushing is used in crusting and low permeability soils to wash away the surface salts using good quality water to remove salts, leaching works well on saline soils having good structure and internal drainage. The alkali/sodic soils are generally reclaimed by leaching of the excess sodium, by deep ploughing to incorporate the calcareous subsoil into the topsoil and by adding acidifying minerals like pyrite and gypsum.

It has been reported that Sulphur (S) assimilation plays a pivotal role in the metabolic modifications that occur under salt stress, and increased $\mathrm{S}$ levels have been shown to increase salt tolerance in plants (Astolfi et al., 2013). S-adenosyl methionine is the precursor of polyamines (PAs), which are closely associated with plant resistance to salinity stress (Chen et al., 2014)

\subsubsection{Waterlogging}

Application of organic manure improves soil physical factors, reduces soil surface crusting, enhances plant rooting and alleviates the effects of pan formation on yield. Increased soil organic content aids in resolving the problem of water logging caused by a higher infiltration rate. Ridge and furrow system or sprinkler irrigation have been shown to reduce the problem of water logging. Growing the plants on ridges helps in keeping the roots away from waterlogged areas while the furrows facilitate proper drainage of fields. It has been observed that adopting conservation agriculture and furrow-irrigated raised-bed planting system also helps to reduce crop lodging.

\subsubsection{PHS}

Weathering of grain mainly due to rainfall after maturity, can lead to PHS. To minimize PHS and test-weight losses the wheat is harvested and dried wheat the first time it reaches when the moisture is at 20 percent, harvesting is done when it contains it the first time it reaches 15 percent moisture. It must be ensured that combine and all other critical equipment including hauling capacity are "ready to roll."

\subsection{Genetic and biotechnological management}

\subsubsection{Drought management}

Drought stress tolerance is a complicated trait that is affected by genetics, as well as a number of quantitative trait loci (QTLs) and environmental influences. Polygenes control the genetic basis of drought resistance, with each gene having a limited and cumulative effect with a high GXE interaction, resulting in low heritability. Drought tolerance has been studied genetically in wheat through the discovery of molecular markers and genome sequencing (Wani et al., 2020). Such analysis includes several approaches e.g. QTL-mapping, association-mapping, genome-wide analyses and expression analysis which aim to identify QTL or gene-related traits for drought stress tolerance. Different DNA molecular markers have been used to genotype the populations and identify QTL (Maccaferri et al., 2008). Recently, a high-density genetic SNP map (SNP array or genotyping by sequencing (GBS)) have been used to genotype the population (Obasa et al., 2016). Numerous QTLs for grain yield on chromosomes one, three, and six, for grain number per spike on chromosomes two, three, and six, and for spikelet number per each spike on chromosomes two, five, and six have been identified. Major QTL monitoring grain yield can be used in marker-assisted selection for yield improvement under drought stress. Wheat varieties DBW 14, K 9107, HD 2733 etc for North Eastern Plain Zone and NI-5439, Raj-3765, WH-147, HD-2733 etc. are identified as drought tolerant for North Western Plain Zone (Meena et al., 2015) of India.

\subsubsection{Heat stress management}

Heat tolerance is obviously a polygenic trait, and the molecular techniques also help in understanding the genetic basis of plant thermo tolerance. Recently several QTLs for different yield component traits have been identified which can be used for developing heat tolerance in wheat. For example, QTLs for heat tolerance has been identified for grain weight and grain-filling duration, senescence related traits and canopy temperature. These QTLs may prove useful for improvement of such traits using Marker Assisted Selection (MAS). Among the wheat varieties Halna is most tolerant wheat genotype followed by K-8962 and Raj-3765, DBW-14 and NW-1014 (Singh et al., 2020; Singh et al., 2019). 


\subsubsection{Salinity stress management}

The available studies led to identification of $\sim 500$ QTL (excluding those involved in digenic epistatic interactions and QTL x treatment interactions); these QTL are spread over all the 21 wheat chromosomes and could prove useful resource for MAS intended at improving salt tolerance in wheat. Wheat gene TaAOC1, encoding cyclase involved in jasmonic acid synthesis, was induced by high salinity. Constitutive expression of TaAOC1 in both wheat and Arabidopsis restricted root growth, but enhanced salt tolerance and Jasmonic acid content. Wheat lines highly tolerant to salinity are Kharchia (from Rajasthan; eg., KR 375, KR 378), Rata (from Bhal, Gujrat), KRL 213 and KRL 210 from CSSRI Karnal.

\subsubsection{Pre-harvest sprouting/dormancy management}

Pre-harvest sprouting (PHS) is a quantitative characteristic controlled by various genes. About 250 QTL were identified, among them just 29 QTL were major and stable across environments; these QTL are conveyed on 11 unique chromosomes (1B, 3A, 4A, 5A, 6A, 2B, 3B, 4B, 7B, 2D, 3D and 7D); the most noteworthy PV explained by an individual QTL range from $23 \%$ to $78.3 \%$. In a report it has been observed that the major PHS resistance QTL Qphs.usask.4A carries three diagnostic SSR marker alleles, DuPw004 (200 bp), barc170 (158 bp) and wmc650 (109 bp) inherited from the dormant parent, while nondormant parent contributed DuPw004 (300 bp), barc170 (177 bp) and wmc 650 (90 bp) alleles. A survey of pedigrees analysis of number of western Canadian wheat cultivars revealed that the parental line RL 4137 is a major source of increased PHS resistance (Singh et al., 2012).

\subsubsection{Waterlogging management}

Water logging tolerant cultivars of wheat were identified (Vijayalakshmi et al., 2010) which unlocks the potential of water logging tolerant variety research of wheat. Presence of $A d h$ gene in wheat which is also found in barley and rice are associated with water logging tolerance to ensure the presence of tolerance mechanism in wheat. It has been reported that possible crosses between water logging tolerant cultivars of spring wheat were made which in turn suggested that water logging is controlled by a few number of genes (Boru et al., 2001). It also has been reported that new allele for aerenchyma formation under waterlogging condition was identifed from a wild barley genotypes. This allele showed a good potential in forming aerenchyma and was the major contributor to waterlogging tolerance (Zhang et al., 2017). A high-density linkage map helped identify several co-segregating markers linked with QTLs for aerenchyma formation in wheat and that can be directly used in breeding programs.

\section{Future Prospects}

The abiotic stresses significantly affect the crop productivity either directly or indirectly. However, the level of crop yield loss due to stresses depends upon the growth stage and period of stress. Stress tolerance potential of genes may differ depending on environmental conditions and their interactions. A systematic and integrative approach of physiology, biology, genomics, and genetic engineering is needed to explain the complex mechanisms of these stresses that are controlled by a large number of genes. To speed up wheat improvement program, the wheat genome sequence information can be used to classify candidate genes responsible for complex agronomic traits. Pyramiding and combination of different QTLs and transgenes through marker-assisted breeding approaches may lead to biotic and abiotic tolerant wheat varieties. Understanding the signalling pathways that are triggered in response to abiotic stress would provide useful knowledge for developing new technologies to reduce yield loss caused by abiotic stress. Plant hormones may also be used as a foliar application or as a pre-seeding therapy. Genome editing with CRISPR/Cas technology will be used during the isolation of suitable mutants to increase overall yield and resistance to biotic and abiotic stresses. Editing of genes like TaGW2, TaGARS7, and TaDEP1 has already demonstrated the usefulness of this process (Liang et al., 2017; Wang et al., 2018a, b; Zhang et al., 2016; Zhang et al., 2018). The use of base editing (a changed CRISPR/Cas approach) in the development of climate-resilient improved wheat cultivars has also been suggested.

\section{Ethical standards}

Not applicable with this article.

\section{Conflict of interest}

The authors declare that they have no conflict of interest.

\section{Author contributions}

SK, SM1 and SM2 designed the concept of the article. SK and $\mathrm{SC}$ prepared the figures used in the article. SK, SM1 and SC wrote the manuscript, SM communicate to the journal time to time. SK and SM1 make the final editing of the review article. 


\section{References}

1. Abhinandan K, L Skori, M Stanic, NMN Hickerson, M Jamshed and MA Samuel. 2018. Abiotic stress signaling in wheat - An inclusive overview of hormonal interactions during abiotic stress responses in wheat. Frontiers in Plant Science 9:734. doi: 10.3389/fpls.2018.00734

2. Acquaah G. 2007. Principles of Plant Genetics and Breeding. Blackwell, Oxford; p. 385

3. Afzal I, S Maqsood, A Basra, N Ahmad and M Farooq. 2005. Optimization of hormonal priming techniques for alleviation of salinity stress in wheat (Triticum aestivum L.). Caderno de PesquisasérieBiologia 17: 95-109.

4. Agarwal S, RK Sairam, GC Srivastava, A Tyagi, and RC Meena. 2005b. Role of ABA, salicylic acid, calcium and hydrogen peroxide on antioxidant enzymes induction in wheat seedlings. Plant Science1 69: 559-570. doi: 10.1016/ j.plantsci.2005.05.004

5. Agarwal S, RK Sairam, GC Srivastava, and RC Meena. 2005a. Changes in antioxidant enzymes activity and oxidative stress by abscisic acid and salicylic acid in wheat genotypes. Biologia Plantarum 49: 541-550.

6. Ahmed F, MY Rafil, MR Ismail, AS Juraimi, HA Rahim, R Asfaliza and MA Latif. 2013. Waterlogging tolerance of crops: Breeding, mechanism of tolerance, molecular approaches, and future prospects. BioMed Research International 1-10.

7. Akter $\mathrm{N}$ and MR Islam. 2017. Heat stress effects and management in wheat. A review. Agronomy for Sustainable Devevelopment 37: 1-7.

8. Armstrong W, R Brändle and MB Jackson. 1994. Mechanisms of flood tolerance in plants. Acta Botanica Neerlandica 43: 307-358.

9. Astolfi S and S Zuchi. 2013. Adequate S supply protects barley plants from adverse effects of salinity stress by increasing thiol contents. Acta physiologiae plantarum 35: 175-181.

10. Awaji S, P Hanjagi and VR Sashidhar. 2019. Improved salt tolerance in rice (Oryza sativa) by co-expression of two vacuolar transporter genes involved in sodium compartmentation and proton gradient generation. Journal of Cereal Research 11(3):215-223. http://doi.org/10.25174/2249$4065 / 2019 / 94888$

11. Azmat A, H Yasmin, MN Hassan, A Nosheen, R Naz, M Sajjad, N Ilyas and MN Akhtar. 2020. Co-application of bio-fertilizer and salicylic acid improves growth, photosynthetic pigments and stress tolerance in wheat under drought stress. Peer J 8:e9960

12. Bakshi S, R Agarwal and S Jambhulkar. 2020. Morpho-physiological characterization of two wheat genotypes with contrasting trait of heat tolerance. Journal of Cereal Research 12(3): 270-280. http://doi. org/10.25174/2582-2675/2020/104899

13. Bandeh-Hagh A, M Toorchi, A Mohammadi, N Chaparzadeh, GH Salekdeh and H Kazemnia. 2008. Growth and osmotic adjustment of canola genotypes in response to salinity. Journal of Food, Agriculture and Environment 6:201-208.

14. Blokhina OB, E Virolainen, and KV Fagerstedt. 2003. Antioxidants, oxidative damage and oxygen deprivation stress: a review. Annals of Botany 91: 179-194

15. Blum A, N Klueva and HT Nguyen. 2001. Wheat cellular thermo tolerance is related to yield under heat stress. Euphytica 117: 117-123

16. Blum A. 1988. Plant Breeding for Stress Environments. CRC Press, Boca Raton, FL.

17. Boru G, M Van Ginkel, WE Kronstad and L Boersma. 2001. Expression and inheritance of tolerance to water logging stress in wheat. Euphytica 117: $91-98$.

18. Bota J, J Flexas and H Medrano. 2004. Is photosynthesis limited by decreased Rubisco activity and RuBP content under progressive water stress? New Phytologist 162: 671-681

19. Brandle R and RMM Crawford. 1987. Rhizome anoxia tolerance and habitat specialisation in wetland plants. In: Crawford RMM (ed) Plant life in aquatic and amphibious habitats. Blackwell, Oxford pp 397-410 
20. Chavas MM.1991. Effect of water deficits on carbon assimilation. Journal of Experimental Botany 42: 1-16.

21. Chen M, JJ Chen, JY Fang, ZF Guo and SY Lu. 2014. Down-regulation of S-adenosylmethionine decarboxylase genes results in reduced plant length, pollen viability, and abiotic stress tolerance. Plant Cell, Tissue Organ Cult 116: 311-322.

22. Annoynous. 2011. Wheat - global alliance for improving food security and the livelihoods of the resource-poor in the developing world: proposal submitted by CIMMYT and ICARDA to the CGIAR Consortium Board. Centro Internacional de Mejoramiento de Maíz y Trigo (CIMMYT) pp iv, 150 .

23. Collaku A and SA Harrison. 2002. Losses in wheat due to waterlogging. Crop Science 42: 444-450

24. Cornic $\mathrm{G}$ and A Massacci.1996. Leaf photosynthesis under drought stress. In: Bakered. NR, ed. Photosynthesis and the Environment, The Netherlands: Kluwer Acedemic Pub. pp. 230

25. Cornic G, J Ghasghaie, B Genty and JM Briantais.1992. Leaf photosynthesis is resistant to a mild drought stress. Photosynthetica 27: 295-309

26. CSSRI. 1997. Vision 2020 - CSSRI perspective plan. CSSRI, Karnal

27. Daveis WJ and J Zhang. 1991. Root signals and the regulation of growth and development of plants in drying soil. Annual Review of Plant Physiology 42: $55-76$.

28. de San Celedonio R, LG Abeledo and D Miralles. 2014. Identifying the critical period for water logging on yield and its components in wheat and barley. Plant and Soil 378: 265-277.

29. Drew MC. 1997. Oxygen deficiency and root metabolism: injury and acclimation under hypoxia and anoxia. Annual Review of Plant Physiology and Plant Molecular Biology 48: 223-250

30. Dubey RS. 1997. Photosynthesis in plants under stressful condition, In: Pessarakli M (ed) Handbook of Photosynthesis, Marcel Dekker, New York, NY ISBN 0-8247-9708-6:859-875

31. Edmeades GO, M Cooper, R Lafitte, C Zinselmeier, JM Ribaut, JEL Habben, C Offler and M Banziger.
2001. Abiotic stresses and staple crops. Crop Science: progress and prospects, Proceedings of the third Inter-national Crop Science Congress, August 18-23, 2000, Hamburg, Germany. pp. 137-154.

32. FAO. 2009. High Level Expert Forum-How to Feed the World in 2050. Economic and Social Development, Food and Agricultural Organization of the United Nations, Rome, Italy;

33. Fardus J, MA Matin, M Hasanuzzaman, MA Hossain, and M Hasanuzzaman. 2018. Salicylic acid-induced improvement in germination and growth parameters of wheat under salinity stress. The Journal of Animal and Plant Sciences 28: 197-207

34. Farooq M, H Bramley, JA Palta and KHM Siddique. 2011. Heat stress in wheat during reproductive and grain-filling phases. Critical Reviewes in Plant Sciences 30: 491-507.

35. Fleet CM, and T Sun. 2005. A Dellacate balance: the role of gibberellin in plant morphogenesis. Current Opinion in Plant Biology 8: 77-85.

36. Garnczarska M. 2005. Response of the ascorbateglutathione cycle to re-aeration following hypoxia in lupine roots. Plant Physiology and Biochemistry 43: 583-590.

37. Groos C, G Gay, MR Perretant, L Gervais, M Bernard, F Dedryver and G Charmet. 2002. Study of the relationship between pre-harvest sprouting and grain color by quantitative trait loci analysis in a whitexred grain bread-wheat cross. Theoretical and Applied Genetics 104: 39-47.

38. Gupta PK, HSBalyan, S Sharma and R Kumar. 2020. Genetics of yield, abiotic stress tolerance and biofortifcation in wheat (Triticum aestivum L.) Theoretical and Applied Genetics 133: 1569-1602.

39. Hasanuzzaman M, K Nahar, A Rahman, TI Anee, MU Alam, TF Bhuiyan, $\mathrm{H}$ Oku and M Fujita. 2017. Approaches to Enhance Salt Stress Tolerance in Wheat. Chapter from the book Wheat Improvement, Management and Utilization In tech open Science: 151-187 doi.org/10.5772/67247

40. Hasanuzzaman M, K Nahar, MM Alam, R Roychowdhury and M Fujita. 2013. Physiological, biochemical, and molecular mechanisms of heat 
Effect of abiotic stresses and mitigation strategy associated with their tolerance in wheat

stress tolerance in plants. International Journal of Molecular Sciences 14: 9643-9684.

41. Hossain MA and SN Uddin. 2011. Mechanisms of water logging tolerance in wheat: Morphological and metabolic adaptations under hypoxia or anoxia. Australian Journal of Crop Science. 5: 1094-1101.

42. Huang B, JW Johnson, DS Nesmith and DC Bridges.1994. Root and shoot growth of wheat genotypes in response to hypoxia and subsequent resumption of aeration. Crop Science 34:1538-1544.

43. Huke RE and EH Huke.1997. Rice Area by Type of Culture South South east, and East Asia a Revised and Updated Database, International Rice Research Institute, Los Banos, Philippines.

44. IPCC (Intergovernmental Panel on Climate Change).2014. Summary for policymakers. In: Stocker TF, Qin D, Plattner GK, Tignor M, Allen SK, Boschung J, Nauels A, Xia Y, Bex V, Midgley PM (eds) Climate change 2013: the physical science basis. Contribution of Working Group I to the Fifth Assessment Report of the Intergovernmental Panel on Climate Change. Cambridge University Press, Cambridge

45. James RA, C Blake, CS Byrtand R Munns. 2011. Major genes for $\mathrm{Na}$ exclusion, Nax1 and Nax2 (wheat HKT1;4 and HKT1;5), decrease $\mathrm{Na}$ accumulation in bread wheat leaves under saline and waterlogged conditions. Journal of Experimental Botany. 62: 2939-2947.

46. Ji X, B Shiran, J Wan, DC Lewis, CLD Jenkins and AG Condon. 2010. Importance of pre-anthesis anther sink strength for maintenance of grain number during reproductive stage water stress in wheat. Plant, Cell and Environment 33: 926-942. doi: 10.1111/j.1365-3040.2010.02130.x

47. Jones HG. 1992. Plants and microclimate: a quantitative approach to environmental plant physiology. Cambridge University Press, Cambridge, UK, 428 pp.

48. Kamboj D, S Kumar, CN Mishra, P Srivastava, G Singh and GP Singh. 2020. Marker assisted breeding in cereals: Progress made and challenges in India. Journal of Cereal Research 12(2): 85-102. http://doi. org/10.25174/2582-2675/2020/104208
49. Khan MIR, N Iqbal, A Masood, TS Per and NA Khan. 2013. Salicylic acid alleviates adverse effects of heat stress on photosynthesis through changes in proline production and ethylene formation. Plant Signaling E Behavior. 8:e26374. doi: 10.4161/ psb.26374

50. Khobra R, HM Mamrutha, K Venkatesh, CN Mishra, RP Meena, SK Singh and GP Singh. 2020. Exogenous melatonin improves seedling vigour and drought tolerance in wheat. Journal of Cereal Research 12(3): 334-337. http://doi.org/10.25174/25822675/2020/104152

51. Kingsbury RW and E Epstein.1984. Selection for salt-resistant spring wheat. Crop Science 24(2):310-315

52. Kosová K, IT Prášil, P Vítámvás, P Dobrev, V Motyka and K Floková. 2012. Complex phytohormone responses during the cold acclimation of two wheat cultivars differing in cold tolerance, winter Samanta and spring Sandra.Journal of Plant Physiology. 169: 567-576. doi: 10.1016/j.jplph.2011.12.013

53. Kumar A, B Bharti, J Kumar, D Bhatia, GP Singh, JP Jaiswal and R Prasad. 2020. Genetic characterization and its association with grain yield in wheat (Triticum aestivum L.) under drought stress. Journal of Cereal Research 12(2):120-128. http://doi. org/10.25174/2582-2675/2020/96419

54. Liang Z, K Chen, T Li, Y Zhang, Y Wang, Q Zhao, J Liu, H Zhang, C Liu, Y Ran, C Gao. 2017. Efficient DNA-free genome editing of bread wheat using CRISPR/Cas9 ribonucleoprotein complexes. Nature Communications 18(1):1-5.

55. Maccaferri M, MCSanguineti, S Corneti, JLA Ortega, MB Salem, J Bort, E De Ambrogio, LFG del Moral, A Demontis, A El-Ahmed. 2008. Quantitative Trait loci for grain Yield and adaptation of durum wheat (Triticum durum Desf.) across a wide range of water availability. Genetics 178: 489-511.

56. Mahapatra S, P Rayanoothala, MK Solanki and S Das. 2020. Wheat Microbiome: Present Status and Future Perspective. In: Solanki M., Kashyap P., Kumari B. (eds) Phytobiomes: Current Insights and Future Vistas. Springer, Singapore. https:// doi.org/10.1007/978-981-15-3151-4_8 
57. Malik AI, TD Colmer, H Lambers, TL Setter and M Schortemeyer. 2002. Short-term waterlogging has long-term effects on the growth and physiology of wheat. New Phytologist 153(2):225-236

58. Manohara KK, S Morajkar and Y Shanbagh. 2020. Genetic analysis of grain yield and its associated traits in diverse salt-tolerant rice genotypes under coastal salinity condition. Journal of Cereal Research 12(3):290-296. http://doi.org/10.25174/25822675/2020/105442

59. Mansfield TJ and CJ Atkinson.1990. Stomatal behavior in water stressed plants. In: Stress Responses in Plants: Adaptation and Acclimation Mechanisms, Alscher RG, Cumming JR (Eds), Wiley-Liss, New York. pp. 241-264

60. Marti J, R Savin and GA Slafer. 2015. Wheat yield as affected by length of exposure to water logging during stem elongation. Journal of Agronomy and Crop Science 201(6):473-486.

61. Meena VS, BR Maurya, RS Meena. 2015.Residual impact of wellgrow formulation and NPK on growth and yield of wheat (Triticum aestivum L.). Bangladesh Journal of Botany. 44(1):143-6.

62. Mehla RS, JK Verma, RK Gupta and PR Hobbs. 2000. Stagnation in the productivity of wheat in the indo-gangetic plains: zero-till-seed-Cum-fertilizer drill as an integrated solution. In Rice-wheat consortium paper series 8. New Delhi: Rice-Wheat Consortium

63. Mehta P, A Jajoo, S Mathur and S Bharti. 2010. Chlorophyll a fluorescence study revealing effects of high salt stress on photosystem II in wheat leaves. Plant Physiology and Biochemistry 48(1):1620.

64. Misra SC and P Varghese. 2012. Breeding for heat tolerance in wheat. In: Singh SS, Hanchinal RR, Singh G, Sharma RK, Tyagi BS, Saharan MS and Sharma I (eds) Wheat: productivity enhance-ment under changing climate. Narosa Publishing House, New Delhi, p 398.

65. Mohanty HK and GS Khush. 1985. Diallel analysis of submergence tolerance in rice, Oryza sativa L. Theoretical and Applied Genetics 70(5):467-473.

66. Morgan RJM, F Williams and MM Wright. 1997. An early warning scoring system for deteching developing critical illness. Clinical Intensive Care 8: 100 .

67. Mudi N, S Mahapatra and S Das. 2016. Assessment of Helminthosporium leaf blight resistance in Barley using diseases stress tolerance index. Indian Phytopathology 69(1): 24-31.

68. Munns R and M Tester. 2008. Mechanisms of salinity tolerance. Annual Review of Plant Biology. 59: 651-681

69. Nagarajan S and J Rane. 2002. Relationship of simulated water stress using senescing agent with yield performance of wheat genotypes under drought stress. Indian Journal of Plant Physiology 7(4):333-337.

70. Nardini A, MT Tyree and S Salleo. 2001. Xylem cavitation in the leaf of Prunus laurocerasus and its impact on leaf hydraulic. Plant Physiology 125: 1700-1709.

71. Noreen S, K Fatima, HUR Athar, S Ahmad and K Hussain. 2017. Enhancement of physiobiochemical parameters of wheat through exogenous application of salicylic acid under drought stress. Journal of Animal and Plant Sciences. 27: 153-163.

72. Obasa BT, J Eglinton, S Coventry, T March, P Langridge and D Fleury. 2016. Genetic analysis of developmental and adaptive traits in three doubled haploid populations of barley (Hordeum vulgare L.). Theoretical and Applied Genetics. 129: 1139-1151

73. Oshino T, S Miura, S Kikuchi, K Hamada, K Yano, M Watanabe and A Higashitani. 2011. Auxin depletion in barley plants under high-temperature conditions represses DNA proliferation in organelles and nuclei via transcriptional alterations. Plant, Cell and Environment 34: 284-290. doi:10.1111/ j.1365-3040.2010.02242.x

74. Pandey GC, HM Mamrutha, R Tiwari, S Sareen, S Bhatia, V Tiwari and I Sharma. 2015. Physiological traits associated with heat tolerance in bread wheat. Physiology and Molecular Biology of Plants 21: 93-99.

75. Qiu Z, J Guo, A Zhu, L Zhang, and M Zhang. 2014. Exogenous jasmonic acid can enhance tolerance of wheat seedlings to salt stress. Ecotoxicology and Environmental Safety. 104: 202-208. doi: .1016/j.ecoenv.2014.03.014 
Effect of abiotic stresses and mitigation strategy associated with their tolerance in wheat

76. Rane J, RK Pannu, VS Sohu, RS Saini, B Mishra, J Shoran, J Crossa, M Vargas and AK Joshi. 2007. Performance of yield and stability of advanced wheat genotypes under heat stress environments of the Indo-Gangetic Plains. Crop Science 47:1561-1573

77. Rebetzke GJ, AF Van Herwaarden, C Jenkins, M Weiss, D Lewis, Ruuska S, L Tabe, NA Fettell. and RA Richards. 2008. Quantitative trait loci for water-soluble carbohydrates and associations with agronomic traits in wheat. Australian Journal of Agricultural Research 59: 891-905

78. Rebetzke GJ, AG Condon, RA Richards and GD Farquahr. 2002. Selection for reduced carbon isotope discrimination increases aerial biomass and grain yield of rain fed bread wheat. Crop Science 42:739-745.

79. Reynolds MP, M Balota, MIB Delgado, I Amani and RA Fischer.1994. Physiological and morphological traits associated with spring wheat yield under hot, irrigated conditions. Australian Journal of Plant Physiology. 21: 717-730.

80. Royo A and D Abió. 2003. Salt tolerance in durum wheat cultivars. Spanish Journal of Agricultural Research 1: 27-35

81. Sakata T, T Oshino, S Miura, M Tomabechi, Y Tsunaga and N Higashitani. 2010. Auxins reverse plant male sterility caused by high temperatures. Proceedings of the National Academy of Sciences of the United States of America. 107: 8569-8574. doi: 10.1073/pnas.1000869107

82. Sallam A, A Alqudah, MFA Dawood, PS Baenziger and A Börner. 2019. Drought stress tolerance in wheat and barley: Advances in physiology, breeding and genetics research. International Journal of Molecular Sciences 20: 3137; doi:10.3390/ ijms20133137

83. Setter TL, M Ellis, EV Laureles, ES Ella, D Senadhira, SB Mishra, S Sarkarung and S Datta. 1997. Physiology and genetics of submergence tolerance in rice.Annals of botany. 79: 67-77

84. Settler TL and I Waters. 2003. Reviews of prospects for germplasm improvement for water logging tolerance in wheat, barley and oats. Plant Soil 253: $1-34$
85. Shanahan JF, IB Edwards, JS Quick and JR Fenwick.1990. Membrane thermo stability and heat tolerance of spring wheat. Crop Science. 30: 247-251.

86. Shankar MS, AV Ramanjaneyulu, TL Nilima and A. 2015. Sprinkler Irrigation - An Asset in Water Scarce and Undulating Areas. Integrated Soil and Water Resource Management for Livelihood and Environmental Sec. pp 259-283

87. Sharma D, HM Mamrutha, VK Gupta, R Tiwari and R Singh. 2015. Association of SSCP variants of HSP genes with physiological and yield traits under heat stress in wheat. Research on crops 16(1):139-146

88. Sharma SK and OP Garg. 1983. Comparative study of osmotic and salt stress effects on nitrate assimilation in wheat. Current Agriculture. 7: 36-40.

89. Sharp RE and WJ Davies.1979. Solute regulation and growth by roots and shoots of water stressed maize plants. Planta 147:43-49

90. Shehrawat S, Y Kumar and J Singh. 2020.Use of multiple stress indices as a measure of heat tolerance in wheat accessions. Journal of Cereal Research12(3):297-308.

91. Sieber M and R Brändle.1991. Energy metabolism in rhizomes of Acorus calamus (L.) and in tubers of Solanum tuberosum (L.) with regard to their anoxia tolerance. Botanica Acta. 104(4):279-282.

92. Singh G, P Kumar, V Gupta, BS Tyagi, C Singh and GP Singh. 2020. Identification and characterization of recombinant inbred lines (RILs) for waterlogging tolerance in bread wheat. Journal of Cereal Research 12(3): 229-238. http://doi.org/ 10.25174/25822675/2020/102300

93. Singh PK, S Prasad, AK Verma, B Lal, R Singh, SP Singh and DK Dwivedi. 2020. Screening for Heat Tolerant Traits in Wheat (Triticum aestivum L.) Genotypes by Physiobiochemical Markers. InternationalJournal of Current Microbiology and Applied Sciences 9(2): 2335-2343.

94. Singh R, P Hucl, M Baga and RN Chibbar. 2012. Validation of Molecular Markers for Preharvest Sprouting Resistance in Bread Wheat Cereal Research Communications 40(2):194-203. 
95. Singh TP, J Kumari, RK Sharma, Shivani, S Kumar and S R Jacob 2019. Morpho-Physiological Diversity in Indian Spring Wheat cultivars and Identification of Promising Donor under Terminal Heat Stress. Journal of Cereal Research 11(2):140-146 doi.org/10.25174/2249-4065/2019/89261

96. Slatyer RO and SA Taylor. 1960. Terminology in plant-soil water relation. Nature 187: 922-924.

97. Smrutishree S, B Bhagawati and Nitesh. 2018. Salinity Tolerance in wheat. Marumegh 3(1): 61-65.

98. Stoll M, B Loveys and P Dry. 2000. Hormonal changes induced by partial root zone drying of irrigated grapevine. Journal of Experimental Botany51:1627-1634.

99. Tardieu F, N Katerji, J Behenod, J Zhang and WJ Davis. 1991. Maize stomatal conductance in the field: its relationship with soil and plant water potentials, mechanical constraints and ABA concentration in the xylem sap. Plant Cell and Environment 14:121-126.

100. Thomason W, KR Hughes, CA Griffey, DJ Parrish and WE Barbeau. 2019. Understanding Preharvest Sprouting of Wheat. Virginia Cooperative Extension pp 124-060. https://www.pubs.ext. vt.edu/424/424-060/424-060.html

101. Tiwari R, S Sheoran, J Rane. 2014. Wheat improvement for drought and heat tolerance. Recent trends on production strategies of wheat in India'.(Eds RS Shukla, PC Mishra, R Chatrath, RK Gupta, SS Tomar, I Sharma) (Directorate of Wheat Research: Karnal, Haryana, India).

102. Tiwari V, HM Mamrutha, S Sareen, S Sheoran, R Tiwari, P Sharma, C Singh, G Singh and J Rane. 2019. Managing abiotic stress in wheat. In: Abiotic Stress Management for Resilient Agriculture(pp.313-337). Springer Nature Singapore Pte Ltd. 2017 P.S. Minhas et al., (eds.), Abiotic Stress Management for Resilient Agriculture, DOI 10.1007/978-981-10-5744-1-14

103. Towill LE and P Mazur.1974. Studies on the reduction of 2, 3, 5-triphenyl tetrazolium chloride as a viability assay for plant tissue culture. Canadian Journal of Botany 53: 1097-1102

104. Tromas A, S Paque, V Stierlé, AL Quettier, P Muller and E Lechner. 2013. Auxin-Binding Protein 1 is a negative regulator of the SCFTIR1/AFB pathway.
Nature Communications 4:2496. doi: 10.1038/ ncomms3496

105. Turner NC. 2001. Optimising water use. In: Nosberger J, Geiger HH and Struik PC (2001) Proceedings of the Third Crop Science Congress on Crop Science Progess and Prospects. CABI international Wallingford pp 119-135.

106. Vignjevic M, X Wang, JE Olesen, B Wollenweber. 2015. Traits in spring wheat cultivars associated with yield loss caused by a heat stress episode after anthesis. Journal of Agronomy and Crop Science. 201(1):32-48.

107. Vijayalakshmi K, AK Fritz, GM Paulsen, G Bai, S Pandravada and BS Gill. 2010. Modeling and mapping QTL for senescence-related traits in winter wheat under high temperature. Molecular Breeding 26:163-175. doi:10.1007/s11032-009-9366-8

108. Wang J, X Meng, X Hu, T Sun, J Li, K Wang, H Yu. 2019.Cas9 expands the scope of genome editing with reduced efficiency in rice. Plant Biotechnology Journal. 17(4):709.

109. Wang S, L He, Z Li , J Zeng, Y Cai and L Hou. 1996. A comparative study of the resistance of barley and wheat to water logging. Acta AgronomicaSinica, 22: 228-232

110. Wani SH, JR Choudhary, M Choudhary, M Rana and SS Gosal. 2020. Recent advances in genomics assisted breeding for drought stress tolerance in major cereals. Journal of Cereal Research 12(1):1-12. http://doi.org/10.25174/2582-2675/2020/100821

111. Wardlaw IF, IA Dawson, P Munibi and R Fewster.1989. The tolerance of wheat to high temperatures during reproductive growth: I. Survey procedures and general response patterns. Australian Journal of Agricultural Research 40:1-13.

112. Wei Q, Q Luo, R Wang, F Zhang, Y He and Y Zhang. 2017. A wheat R2R3-type MYB transcription factor TaODORANT1 positively regulates drought and salt stress responses in transgenic tobacco plants. Frontiers in Plant Science 8:1374. doi: 10.3389/ fpls.2017.01374

113. Wheeler T and J Von Braun. 2013. Climate change impacts on global food security. Science 341:508-513. doi:10.1126/science.1239402 
Effect of abiotic stresses and mitigation strategy associated with their tolerance in wheat

114. Wheeler TR, G Batts, RH Ellis, P Haley and JH Morison. 1996. Growth and yield of winter wheat (Triticum aestivum) crops in response to $\mathrm{CO}_{2}$ and temperature. Journal of Agricultural Science (Camb) 127:37-48

115. Wilkinson S and WJ Davies. 2010. Drought, ozone, ABA and ethylene: new insights from cell to plant to community. Plant, Cell and Environment 33:510-525

116. Wilkinson S, GR Kudoyarova, DS Veselov, TN Arkhipova, and WJ Davies. 2012. Plant hormone interactions: innovative targets for crop breeding and management. Journal of Experimental Botany 63: 3499-3509. doi: 10.1093/jxb/ers 148

117. $\mathrm{Xu} \mathrm{W,} \mathrm{DT} \mathrm{Rosenow} \mathrm{and} \mathrm{HT} \mathrm{Nguyen.} \mathrm{2000.} \mathrm{Stay-}$ green trait in grain sorghum: Relationship between visual rating and leaf chlorophyll concentration. Plant Breeding 119: 365-367

118. Yadav AK, AJ Carroll, GM Estavillo, GJ Rebetzke and BJ Pogson. 2019. Wheat drought tolerance in the field is predicted by amino acid responses to glasshouse-imposed drought. Journal of Experimental Botany 70(18):4931-48.

119. Yang W, Y Li, Y Yin, Z Qin, M Zheng and J Chen. 2017. Involvement of ethylene and polyamines biosynthesis and abdominal phloem tissues characters of wheat caryopsis during grain filling under stress conditions. Scientific Reports 7:46020. doi: 10.1038/srep46020

120. Zang X, W Pei, M Wu, Y Geng, N Wang, G Liu, J Ma, D Li, Y Cui, X Li, J Zhang. 2018.Genome-scale analysis of the WRI-like family in Gossypium and functional characterization of GhWRI1a controlling triacylglycerol content. Frontiers in Plant Science 9:1516.

121. Zhang X, Y Fan, S Shabala, A Koutoulis, L Shabala, $\mathrm{P}$ Johnson, $\mathrm{H} \mathrm{Hu}$ and $\mathrm{M}$ Zhou. 2017. A new major-effect QTL for waterlogging tolerance in wild barley (H. spontaneum). Theoretical and Applied Genetics 130:1559-1568. https://doi.org/10.1007/ s00122-017-2910-8

122. Zhang Y, Z Liang, Y Zong, Y Wang, J Liu, K Chen, JL Qiu and C Gao. 2016. Efficient and transgenefree genome editing in wheat through transient expression of CRISPR/Cas9 DNA or RNA. Nature Communications 7(1):1-8.

123. Pandey GC, G Mehta, P Sharma and V Sharma. 2019. Terminal heat tolerance in wheat: An overview. Journal of Cereal Research 11(1):1-16 doi. org/10.25174/2249-4065/2019/79252

124. Devi R, S Ram, A Verma, V Pande and GP Singh. 2018. Identification of physiological traits at seedling stage associated with salt tolerance in wheat variety KH65 using RILs. Wheat and Barley Research 10(2):108-114. doi.org/ 10.25174/22494065/2018/79735

125. Jasrotia P, PL Kashyap, AK Bhardwaj, S Kumar and GP Singh. 2018. Scope and applications of nanotechnology for wheat production: A review of recent advances. Wheat and Barley Research 10(1):114. doi.org/10.25174/2249-4065/2018/76672.

126. Kavita, R, NK Munjal, and SS Dhanda. 2016. Stress response behavior in different wheat species in relation to heat tolerance. Journal of Wheat Research 8(2):49-53.

127. Shukla RS, PC Mishra, R Chatrath, RK Gupta, SS Tomar and I Sharma. 2014. Recent trends on production strategies of wheat in India, Indian Institute of Wheat and Barley Research, pp 39-58

128. Zhang S, R Zhang and G Song. 2018. Targeted mutagenesis using the Agrobacterium tumefaciensmediated CRISPR-Cas9 system in common wheat. BMC Plant Biology 18:302

129. Baum M, W Tadesse, M Nachit, O Abdalla, S Rajaram, R Singh, T Payne, K Ammar, L Morgounov and H Braun. 2015. Global Crop Improvement Networks to Bridge Technology Gaps. In: Advances in Wheat Genetics: From Genome to Field pp 387-399

130. Wang R, Y Liu, K Isham, W Zhao, J Wheeler, N Klassen, Y Hu, J. M Bonman, J Chen. 2018. QTL identification and KASP marker development for productive tiller and fertile spikelet numbers in two high-yielding hard white spring wheat cultivars. Molecular Breeding 38:135. https://doi. org/10.1007/s11032-018-0894-y 